\title{
Whither lung EIT: where are we, where do we want to go, and what do we need to get there?
}

\author{
Andy Adler ${ }^{1}$, Marcelo B Amato ${ }^{2}$, John H Arnold ${ }^{3}$, Richard \\ Bayford $^{4}$, Marc Bodenstein ${ }^{5}$, Stephan H Böhm ${ }^{6}$, Brian H \\ Brown $^{7}$, Inéz Frerichs ${ }^{8}$, Ola Stenqvist ${ }^{9}$, Norbert Weiler ${ }^{8}$, \\ Gerhard K Wolf ${ }^{3}$ \\ ${ }^{1}$ Systems and Computer Engineering, Carleton University, Ottawa, Canada \\ ${ }^{2}$ Respiratory Intensive Care Unit, Pulmonary Division, Hospital das Clinicas, \\ University of Sao Paulo, Brazil ${ }^{3}$ Division of Critical Care Medicine, Department of \\ Anesthesia, Children's Hospital Boston, Harvard Medical School, Boston, MA, USA \\ ${ }^{4}$ Department of Natural Sciences, Middlesex University, London, UK ${ }^{5}$ Klinik für \\ Anästhesiologie, Universitätsmedizin Mainz, Germany ${ }^{6}$ swisstom AG, Landquart, \\ Switzerland ${ }^{7}$ Medical Physics, University of Sheffield, UK ${ }^{8}$ Department of \\ Anaesthesiology and Intensive Care Medicine, University Medical Centre \\ Schleswig-Holstein, Campus Kiel, Kiel, Germany ${ }^{9}$ Department of Anaesthesia and \\ Intensive Care Medicine, Sahlgrenska University Hospital, Gothenburg, Sweden
}

\begin{abstract}
Breathing moves volumes of electrically insulating air into and out of the lungs, producing conductivity changes which can be seen by electrical impedance tomography (EIT). It has thus been apparent, since early EIT research, that imaging of ventilation could become a key clinical application of EIT. In this paper, we review the current state and future prospects for lung EIT, by a synthesis of the presentations of the authors at the "special lung sessions" of the annual biomedical EIT conferences in 2009-2011. We argue that lung EIT research has arrived at an important transition. It is now clear that valid and reproducible physiological information is available from EIT lung images. We must now ask the question: how can these data be used to help improve patient outcomes? To answer this question, we develop a classification of possible clinical scenarios in which EIT could play an important role, and we identify clinical and experimental research programs and engineering developments required to turn EIT into a clinical useful tool for lung monitoring.
\end{abstract}

\section{Introduction}

We present an assessment of electrical impedance tomography (EIT) as a tool to guide clinical decision making when managing ventilated patients; we summarize the current state of knowledge, and develop a list of experimental and engineering research and development priorities to ensure EIT is ready for routine clinical use. This paper represents a synthesis of a series of presentations at the "special lung session" of the annual biomedical EIT conferences; the authors were keynote speakers and session 
organizers during the 2009-2011 conferences, and are listed in alphabetical order. Regarding conflicts of interest, amongst the authors are affiliations with most companies active in this area.

EIT uses electrical currents to probe the conductivity distribution within a body from voltage measurements on its surface. This concept was invented for mineral exploration in 1912 (Allaud and Martin, 1977) and then adapted as a medical instrumentation technique (Henderson and Webster, 1978). From early days in EIT research, it has been clear that the technology was well suited to image the lungs - since these are large organs, close to the body surface, into and out of which physiologically large volumes of conductivity contrasting air flows. EIT is non-invasive, rapid (1050 images/s), relatively simple to use, and not cumbersome, enabling its utility as a monitoring technology for intensive care, surgical and emergency patients. It is thus surprising, perhaps, that it took until the late 1990s for a significant medical interest in EIT to develop. In our view, medical interest began in earnest after, a) the injurious effects of mechanical ventilation on lung tissue were identified, b) the realization of the heterogeneous distribution of lung mechanical properties in acute lung injury, c) research showed the importance of lung protective ventilation (LPV), d) EIT became capable of functional real-time imaging, e) EIT image quality reached a sufficient level, and f) an adequate number of devices with adequate performance became available.

To clarify the progression of interest in the clinical use of EIT for monitoring of breathing, we show (figure 1) the annual number of publications on lung EIT and compare it with the ones on ventilator-induced/associated lung injury (VILI/VALI) and on LPV strategies. A clear inflection point is seen in all graphs where the publication rate increases dramatically. For VILI/VALI, this point occurred near 1995, while it occurred about five years later for LPV and lung EIT. We explain this relationship as a result of the increasing awareness of the risks of mechanical ventilation motivating both a search for improved care strategies (LPV, aiming at reducing the injurious effect of mechanical ventilation) and technologies (lung EIT, to monitor ventilation and guide care).

Patients in respiratory failure require positive pressure ventilation to ensure adequate gas exchange. While mechanical ventilation is a life-saving therapy, it also imposes significant risks, due to the possibility of overdistension of small lung units (volutrauma) or by forcing collapsed lung tissue to repeatedly open and close with each breath (tidal recruitment, leading to atelectrauma). These processes may induce an inflammatory cascade and repair processes termed biotrauma. This awareness triggered extensive research into potential solutions, the most important ones being LPV strategies. A key concept of LPV is to implement a patient specific combination of ventilation parameters such as airway pressure, tidal volume, respiratory rate and inspiration-to-expiration time ratio in order to overcome lung collapse and maintain recruitment while avoiding the overdistension of lung regions and still securing sufficient 
gas exchange. Implementing such a strategy ideally requires an on-line monitoring tool capable of providing information on the regional behaviour and recruitability of lung tissue. Thus, the vision driving much of lung EIT research was and still is to create a monitoring tool to help guide and optimize lung protective ventilation individually for each patient.

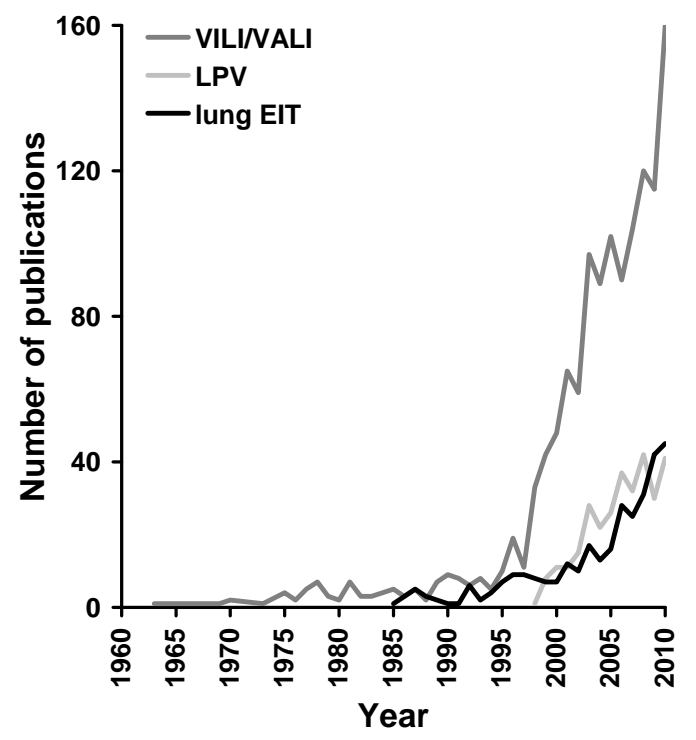

Figure 1. Number of publications on ventilator-induced lung injury or ventilatorassociated lung injury (VILI/VALI), lung protective ventilation (LPV) and lung electrical impedance tomography (EIT) published in peer-reviewed journals. (Source: ISI Web of Knowledge, Thomson Reuters, New York, USA.)

Given the large and growing level of current interest in EIT to monitor and guide ventilation, we ask "whither lung EIT?" or "what does the future hold for EIT?". We critically assess the use of EIT as a tool to optimize mechanical ventilation for patients, and ultimately improve their outcomes. In the following sections we ask "where are we?", "where do we want to go?", and "how do we get there?". In this paper, we adopt the point of view of the clinical user: technology is not interesting for its own sake, or because it can make pretty pictures. Instead, any new instrument must be justified by how it helps the clinical team to take better decisions when treating their patients. EIT information must be timely, easy to understand, reliable, and lead to clinically meaningful diagnosis. Equipment must be available and robust and must justify its direct and indirect costs, thereby enabling improved, and, ideally, faster and thus less expensive, care. 
Table 1. Technological maturity levels for a monitoring technology such as EIT

\begin{tabular}{|c|c|c|}
\hline \multicolumn{3}{|c|}{ Level Description } \\
\hline 0 & Concept for technology & \multirow{6}{*}{$\begin{array}{l}\text { Goal: } \\
\text { accurate } \\
\text { technology } \\
\text { (retrospec- } \\
\text { tive) }\end{array}$} \\
\hline 1 & Promising simulation results & \\
\hline 2 & Phantom experimental results & \\
\hline 3 & Pilot in-vivo studies & \\
\hline 4 & Animal experiments validated to standards & \\
\hline 5 & Consistent studies showing accurate/robust results & \\
\hline 6 & Experimental studies managing animals with technology & \multirow{5}{*}{$\begin{array}{l}\text { Goal: useful } \\
\text { technology } \\
\text { (prospective) }\end{array}$} \\
\hline 7 & Prospective studies managing patients with technology & \\
\hline 8 & Consensus on therapeutic use of technology & \\
\hline 9 & Numerous/multicentre studies linking use of technology to outcomes & \\
\hline 10 & Routine clinical use and consensus on interpretation & \\
\hline
\end{tabular}

\section{Where are we?}

In this section we summarize the current state of knowledge in EIT for lung monitoring, using a categorization based on the type of physiological information EIT is able to provide and our assessment of the degree of technological development currently achieved. This section is not intended to give a full review of existing literature, as this would be beyond the scope of this article.

\subsection{State of experimental/clinical evidence}

We first identify and describe the different types of thoracic physiological information which EIT may be able to provide, and some capabilities and issues associated with each application. We then rate, in our opinion, the maturity of the technology, using the scale $0-10$ of table 1 . As an example of an established technology we may consider electrocardiography, which is also based on surface electrode measurements. In ECG monitoring, electrode types, placement, recording parameters and the test protocol are standardized. In clinical use, ECG measurements are analyzed and presented in a predefined way, with a focus on extracting values relevant to clinical diagnosis and decision making. The potential failure modes of the equipment are well understood. At the same time, new research is exploring novel parameters and uses of these ECG data. We compare ECG to EIT monitoring in table 2.

Based on these levels of technological maturity, we classify and describe the fields of use which have been proposed for thoracic EIT. Table 3 is classified according the classical categories of respiratory function (Barret et al 2009, Hall 2011, Schmidt et al 2011), and describes the respiratory function, measurement goal, capabilities and issues of each potential application of EIT. Respiratory function is separated into categories (distribution of tidal volume, intrathoracic gas volume, and respiratory system 
Table 2. Comparison of an established (ECG) and non-established medical technology (EIT). To illustrate the use of both methods, clinical examples (myocardial infarction and overdistension of lung regions, respectively) are shown in each setting.

\begin{tabular}{|c|c|c|}
\hline & ECG: (established use) & EIT: (suggested use) \\
\hline $\begin{array}{l}\text { Standardized } \\
\text { examination, } \\
\text { evaluation, } \\
\text { nomencla- } \\
\text { ture and } \\
\text { output }\end{array}$ & $\begin{array}{l}\text { - Placement of electrodes } \\
\text { - Colour coding and labelling of elec- } \\
\text { trodes } \\
\text { ○ Signal calibration (time, voltage) } \\
\text { - Signal processing (filtering) } \\
\text { - Waveforms (12 leads,: I, II, III, aVL, } \\
\text { aVR, aVF, V1-V6) } \\
\text { - Analysis (P wave, QRS complex, T } \\
\text { wave, intervals and segments, rhythm, } \\
\text { etc.) }\end{array}$ & $\begin{array}{l}\text { - Location of electrode plane } \\
\text { - Colour coding of leads, or indicator or } \\
\text { electrode sequence, or belts } \\
\text { - Signal calibration (gas volume, airway } \\
\text { pressure) } \\
\text { - Signal processing (filtering, regions of } \\
\text { interest) } \\
\text { - Waveforms (regions of interest) } \\
\text { - Analysis (anterior-to-posterior venti- } \\
\text { lation and compliance profile, curvi- } \\
\text { linearity of regional lung filling and } \\
\text { emptying, regional tidal volume) } \\
\text { - Ventilation manoeuvre (e.g. increase } \\
\text { in PEEP } 5 \mathrm{cmH}_{2} \mathrm{O} \text { ) } \\
\text { - Functional scans }\end{array}$ \\
\hline $\begin{array}{l}\text { Well defined } \\
\text { findings and } \\
\text { interpretation } \\
\text { scheme }\end{array}$ & $\begin{array}{l}\text { - ST segment elevation in lead I, aVL, } \\
\text { V2 and V3 } \\
\text { - Extrasystoles }\end{array}$ & $\begin{array}{l}\text { - Shift in ventilation towards dependent } \\
\text { regions } \\
\text { - Increased curvilinearity (deceleration) } \\
\text { of regional lung filling in non- } \\
\text { dependent regions } \\
\text { - Fall in regional tidal volume and } \\
\text { compliance in non-dependent regions }\end{array}$ \\
\hline $\begin{array}{l}\text { Combination } \\
\text { with other } \\
\text { findings }\end{array}$ & $\begin{array}{l}\text { - Symptoms (acute chest pain, dysp- } \\
\text { noea) } \\
\text { - Physical examination } \\
\text { - Laboratory results (biomarkers) } \\
\text { - Echocardiography } \\
\text { - Coronary angiography }\end{array}$ & $\begin{array}{l}\text { - Respiratory system mechanics } \\
\circ \mathrm{O}_{2} \text { saturation } \\
\circ \text { Blood gas analysis } \\
\text { - Laboratory results (inflammation, } \\
\text { collagen production biomarkers). }\end{array}$ \\
\hline Diagnosis & - Myocardial infarction (anterior wall) & $\begin{array}{l}\text { O Overdistension of non-dependent lung } \\
\text { regions }\end{array}$ \\
\hline Therapy & $\begin{array}{l}\text { Oxygen therapy } \\
\text { - Percutaneous coronary intervention } \\
\text { - Fibrinolysis } \\
\text { - Medication }\end{array}$ & $\begin{array}{l}\text { - Reduction in inspiratory pressure } \\
\text { - Reduction of tidal volume } \\
\circ \text { PEEP adjustment } \\
\circ \text { Enhanced } \mathrm{CO}_{2} \text { removal } \\
\text { - Positioning Therapy } \\
\circ \text { Physical Therapy }\end{array}$ \\
\hline
\end{tabular}


mechanics) which were controlled directly by the respective ventilator parameters (tidal volume, PEEP and lung compiliance) Using this analysis, we summarize the fields of use and application maturity into two broad categories.

- Monitoring ventilation (including respiratory system mechanics, and intrathoracic lung volume changes) is at a level which supports some confidence in its accuracy and repeatability. It is ready for the next step: prospective use as a tool to guide therapy (and we note that some work in this direction is underway).

- Monitoring perfusion and gas exchange is at an earlier level, but shows important promise. These applications are seeing continued experimental validation to understand their accuracy and limitations.

\subsection{State of technology}

Many EIT systems have been developed and used for lung monitoring; most have been developed by academic groups with a focus on research, but recently, commercial systems have been introduced. We clarify the authors' relationships with producers of EIT equipment used in clinical measurements in table 4. The applications, capabilities and issues of table 3 are based on current EIT hardware and imaging technology, which is largely derived from the original Sheffield EIT system (Brown and Seagar, 1987). In all current EIT systems designed for thoracic use, there are, as in the Sheffield system, a small number $(8-32)$ of electrodes placed in a transverse plane around the thorax, and current is driven across electrode pairs while differential voltages are measured. Similarly, image reconstruction approaches are based on linear, one-step reconstruction algorithms, structurally similar to the Sheffield backprojection algorithm. At the same time, we also acknowledge the important progress of the last 30 years. Current EIT systems have greatly reduced noise and interference, are capable of making measurements at much higher rates (sufficient for analysis of both ventilation and perfusion) and recent image reconstruction algorithms provide improved resolution and robustness to electrode errors with reduced image artefacts (Adler et al 2009, Bodenstein et al 2009, Borges et al 2009, Costa et al 2009).

There are several advanced EIT hardware and image reconstruction and analysis concepts being proposed which have yet to be systematically tested in reproducible technical verification environments, and validated in experimental or clinical lung EIT scenarios. This is perhaps due to an unfortunately common disconnect between the research teams in experimental and clinical lung EIT on the one hand, and their mathematical and engineering colleagues on the other. 
Table 3. Assessment of fields of use proposed for thoracic EIT

\begin{tabular}{|c|c|c|c|}
\hline Respir. function & Measurement goal & Capabilities & Issues/dependence on \\
\hline $\begin{array}{l}\text { Ventilation: } \\
\text { 1) Distribution of } \\
\text { tidal volume }\end{array}$ & $\begin{array}{l}\circ \text { heterogeneity due to } \\
\text { lung pathology } \\
\circ \text { overinflation } \\
\circ \text { tidal recruitment } \\
\circ \text { alarm conditions }\end{array}$ & $\begin{array}{l}\circ \text { measuring ventilation distribution } \\
\text { - regions of overdistension, collapse and tidal } \\
\text { recruitment } \\
\circ \text { alarm conditions, such as one-sided ventila- } \\
\text { tion, pneumothorax }\end{array}$ & $\begin{array}{l}\text { - level of the studied chest plane } \\
\text { - effect of blood and fluid redistribution } \\
\text { during ventilatory manoeuvres } \\
\text { - posture \& diaphragm position } \\
\text { - filtering to remove perfusion artefacts }\end{array}$ \\
\hline $\begin{array}{l}\text { 2) Intrathoracic } \\
\text { gas volume (abso- } \\
\text { lute and relative } \\
\text { changes) }\end{array}$ & $\begin{array}{ll}\circ & \text { overinflation } \\
\circ & \text { atelectasis } \\
\circ & \text { recruitment } \\
\circ & \text { derecruitment }\end{array}$ & $\begin{array}{l}\text { measuring regional relative changes in lung } \\
\text { volumes } \\
\text { - detecting regions of overinflation, recruitment } \\
\text { and derecruitment }\end{array}$ & $\begin{array}{l}\text { - level of the studied chest plane } \\
\text { - posture \& diaphragm position } \\
\text { - intrathoracic fluid and blood content } \\
\text { - no reference values for absolute } Z \\
\text { - assumption of isotropic lung expansion }\end{array}$ \\
\hline $\begin{array}{l}\text { 3) Respiratory } \\
\text { system mechanics } \\
\text { (static and dy- } \\
\text { namic behaviour } \\
\text { of lungs) }\end{array}$ & $\begin{array}{l}\circ \text { heterogeneous tissue } \\
\text { properties } \\
\circ \text { overinflation } \\
\circ \text { atelectasis } \\
\circ \text { tidal recruitment }\end{array}$ & $\begin{array}{l}\circ \text { regional compliance }(\Delta \mathrm{Z} / \Delta \mathrm{P}) \\
\circ \text { opening and closing pressures, time delay in } \\
\text { ventilation } \\
\circ \text { other filling and emptying characteristics } \\
\circ \text { intratidal dynamics }\end{array}$ & $\begin{array}{l}\circ \text { use of global pressure with regional } \Delta Z \\
\circ \text { posture } \\
\circ \text { level of studied chest plane } \\
\circ \text { filtering algorithm used }\end{array}$ \\
\hline $\begin{array}{l}\text { Perfusion: } \\
\text { 1) Blood flow }\end{array}$ & $\begin{array}{l}\text { regional distribution of } \\
\text { blood flow in the lung. } \\
\text { perfusion defects } \\
\circ \text { perfusion timing }\end{array}$ & $\begin{array}{l}\text { continuous measurement of pulsatility } \\
\text { (regional changes in blood distribution) } \\
\text { measurement of regional blood flow based on } \\
\text { indicator (hypertonic saline) dilution }\end{array}$ & $\begin{array}{l}\text { - pulsatility correlates with perfusion, but } \\
\text { the measures can diverge } \\
\text { - hypertonic saline may be too invasive } \\
\text { - technique not validated in patients }\end{array}$ \\
\hline $\begin{array}{l}\text { 2) Hemodynamic } \\
\text { parameters }\end{array}$ & $\begin{array}{l}\text { - cardiac output } \\
\text { - } \text { systemic blood pressure } \\
\text { - intravascular fluid } \\
\text { responsiveness }\end{array}$ & $\begin{array}{l}\text { o detection of heart-lung interaction } \\
\circ \text { dynamics seen with advanced filters } \\
\text { o hemodynamic monitoring during fast- } \\
\text { changing clinical conditions }\end{array}$ & $\begin{array}{l}\text { - signal levels are low } \\
\text { ○ early results, not validated in patients }\end{array}$ \\
\hline $\begin{array}{l}\text { Gas exchange: } \\
\text { 1) Ventilation- } \\
\text { perfusion match }\end{array}$ & $\begin{array}{l}\circ \text { regional gas exchange } \\
\circ \text { regional ventilation- } \\
\text { perfusion ratio }\end{array}$ & $\begin{array}{l}\text { ventilation-perfusion match using hypertonic } \\
\text { saline bolus injections, and frequency filtering } \\
\circ \text { measuring oxygen uptake }\end{array}$ & $\begin{array}{l}\text { - EIT signals from ventilation may over- } \\
\text { whelm those from perfusion } \\
\text { ○ early results, not validated in patients }\end{array}$ \\
\hline 2) Oedema & $\begin{array}{l}\text { - assessment of extra- } \\
\text { vascular lung water }\end{array}$ & $\begin{array}{l}\circ \text { decrease in } Z \text { due to oedema } \\
\text { - differentiation between fluid and tissue by } \\
\text { frequency-difference EIT }\end{array}$ & $\begin{array}{l}\text { - difficulty distinguishing collapsed from } \\
\text { oedematous tissue } \\
\text { ○ early results, not validated in patients }\end{array}$ \\
\hline
\end{tabular}


Table 4. EIT equipment used in clinical studies by the authors

\begin{tabular}{|c|c|c|}
\hline Manufacturer & EIT system & Authors using system \\
\hline Dräger Medical $^{1}$ & PulmoVista $500^{*}$ (16 electrode belt) & JHA, OS, GW \\
\hline Timpel SA ${ }^{2}$ & Enlight* (32 electrode belt) & MBA, SHB \\
\hline $\begin{array}{l}\text { Uni. Göttingen } \\
\quad \text { (also CareFusion }^{3} \text { ) }\end{array}$ & Goe MF II* (16 electrode) & $\begin{array}{l}\mathrm{AA}, \mathrm{JHA}, \mathrm{RB}, \mathrm{MB} \\
\mathrm{IF}, \mathrm{NW}, \mathrm{GW}\end{array}$ \\
\hline Uni. Montréal & Sigmatome III (16 electrode) & $\mathrm{AA}$ \\
\hline $\begin{array}{l}\text { Uni. Sheffield } \\
\left(\text { also Maltron } \operatorname{Inc}^{4}\right)\end{array}$ & $\begin{array}{l}\text { Mark } 1 \text { (16 electrode }) \\
\left.\text { Mark } 3.5^{*} \text { ( } 8 \text { electrode }\right)\end{array}$ & $\mathrm{BB}, \mathrm{IF}$ \\
\hline
\end{tabular}

${ }^{*}$ commercial system ${ }^{1}$ Lübeck, Germany ${ }^{2}$ São Paulo, Brazil ${ }^{3}$ Höchberg, Germany ${ }^{4}$ Rayleigh, UK

Examples of such promising technologies are, for EIT Hardware: 3D EIT systems, using multiple bands of electrodes and designed to create a 3D image of conductivity changes in a larger section of the lungs (Metheral et al 1996), and multi-frequency EIT systems, making EIT measurements at multiple stimulation frequencies to detect and image the characteristic differences between tissue types (Brown et al 1994). Lung EIT has seen little exploration of these ideas, and the majority of EIT studies have been performed using single electrode plane single-frequency systems. However, we note that such examinations provide large amounts of information to be interpreted by a clinical user.

For image reconstruction algorithms, technology examples are: algorithms formulated to preserve edges (Borsic et al 2010, Rahmati et al 2011) and use robust data norms (Borsic and Adler 2009), which promise higher quality images with reduced sensitivity to data errors. Reconstruction of absolute EIT images would provide very useful data on the state of lung tissue and its absolute volume (with the promise of a Hounsfield-like unit). Unfortunately, absolute lung EIT has seen relatively little success, largely due to inexactly known electrode positions and contact impedance, and movement during breathing and posture change, even though such absolute images are routinely attempted in breast and head EIT. One promising approach is to fit a smaller number of absolute EIT parameters (such as heart and lung ROIs) onto which the dynamic EIT image may be superimposed (Nebuya et al 2006).

One area of technological development which we feel shows significant promise is novel image analysis algorithms with a particular emphasis on the analysis of dynamic behaviour. The relatively high acquisition rate of modern EIT systems, and the availability of powerful temporal filtering techniques, means that small differences in the dynamic behaviour of tissues can be detected. Such algorithms, allow measurement, for example of pressure-volume curves (Kunst et al 2000, van Genderingen et al 2003), regional time constants (Pulletz et al 2009), regional opening and closing pressures (Kunst et al 2000, Pulletz et al 2011), regional respiratory system compliance (Costa 
et al 2009, Dargaville et al 2010, Lowhagen et al 2010), ventilation delay (Wrigge et al 2008, Victorino et al 2004), regional intratidal gas distribution (Lowhagen et al 2010), and potentially recruitable lung volume (Lowhagen et al 2011). One important advance in such image analysis algorithms is that the EIT output to specific ventilator protocols is analyzed (for example the regional opening pressure in response to slow flow inflation or PEEP trials). EIT signals corresponding to specific physiological processes may be distinguished from background events by QRS gating to measure the pulsatility in the lung regions, or to calculate the stroke volume (Vonk-Noordegraaf et al 2000, Smit et al 2003). Recently, non-linear frequency filtering approaches were developed to determine pulse arrival times (Solà et al 2011, who fit a parameterized function to temporal signals), regional lung blood flow (Borges et al 2011, who identified the maximum slope after bolus injection), and heart-lung interactions (Maisch et al 2011). Various EIT measures can be derived from such measurements performed during specific manoeuvres, and also during continuing artifical ventilation. Not all of these measures enable the assessment of all relevant phenomena at once (e.g. alveolar recruitment, cyclic opening and closing, overdistension), and thus a combination of some indices might be useful.

While such advances promise increased clinical capabilities, and we want to encourage their development, such capabilities are not part of "where we are today". For current systems, we consider the following capabilities to not be sufficiently robust (primarily due to hardware limitations, such as measurement errors and drift, and unknown shape and electrode positions): 1) absolute impedance (and measures of lung volumes, in particular functional residual capacity (FRC)) which is too sensitive to the exact body shape, electrode positions, contact impedances, and 3D conductivity outside of the electrode plane, and 2) prolonged comparison to a previous reference to measure slow changes in volume status over the range of hours to days, primarily due to drift in measurement electronics, slow changes in electrode-skin contact impedance, and body shape changes due to postural shifts.

However, despite the limitations of today's technology (at the hardware and image reconstruction level), there is clear experimental evidence that current EIT systems are of sufficient quality for clinically useful lung measurements, and especially for monitoring of ventilation. In the remainder of this paper, we therefore focus on EIT for ventilation monitoring. Here, EIT is ready to go from retrospective analysis of its accuracy to prospective guidance for patient therapy. We are ready to move from asking, "Can we measure?" to "Can we guide therapy?".

\section{Where do we want to go?}

Clinical interest in EIT is motivated by the fact that the information it provides is intuitively useful to understand patients' regional lung function and the way tissue responds to changes in ventilator settings. The challenge, therefore, is to move from this intuitive understanding, to specific testable predictions of how EIT derived parameters 
may lead to clinical diagnosis and then be used to guide treatment and, finally, to improve patient outcomes. We want to move along a process which we label mnemonically as follows: Reliable (i.e. corresponds to gold standards) $\rightarrow$ Reproducible $\rightarrow$ Relevant (i.e. calculates parameters relevant to clinical practice) $\rightarrow$ Rewarding (i.e. improves outcomes).

In the longer term, we envision EIT being used as a monitoring technology in two main ways. First, it would be part of standard operating procedures (SOPs) in which parameters derived from EIT images would be monitored, and ventilation settings modified according to established clinical evidence. For example, a parameter (percentage of lung collapse) could be identified as a predictor of risk, and a recommendation to perform a recruitment manoeuvre and/or increase positive endexpiratory pressure (PEEP) be given whenever certain threshold values are reached. Next, EIT values would become part of automated systems to control ventilation, in order to better manage the acute and weaning phases of mechanical ventilation. EIT parameters of physiological events such as lung collapse or heart-lung interaction would allow improvements in the safety and performance of such automated systems. To enable such clinically useful EIT, we identify the following requirements:

- availability: EIT devices must be readily available at a reasonable cost. Since EIT uses components common to consumer electronics, increases in volume should strongly reduce costs.

- standards: EIT data and images must be accessible in standard formats. For images, the natural format is a DICOM class.

- robustness: EIT systems must be robust against electrode contact problems and electrical interference. Systems must automatically compensate (if possible) for electrode errors or give appropriate warnings.

- useful software: Software must have an intuitive interface focused on the clinical user. The acceptance of calculated EIT parameters might be increased if they were related to (or reliably calibrated to) those commonly used in clinical practice (corresponding to pressures, volumes, time, or fractions) and not just to changes in impedance. Analysis must be on-line (not retrospective).

- standardized procedures: The specific protocols in which EIT is used need standardization (e.g. in case of a PEEP trial: total duration, duration of individual PEEP steps, magnitude of PEEP steps, type of ventilation, i.e. volume- or pressurecontrolled, required EIT frame rates, additional measurements). This would clarify the measurement context, conditions, clinical and ventilator protocol by analyzing not only EIT data, but other synchronized measures like pressure, volume, and ECG. Standardization should include definitions of included and excluded regions of interest (Pulletz et al 2006, Frerichs et al 2009, Zhao et al 2009). To enhance clinical decision making, automated approaches for data analysis and interpretation should be included. 
Asking the question, "How could EIT improve outcomes?" we have "brainstormed" to collect a list of feasible and clinically useful potential applications of EIT-based parameters. We hypothesize that:

- EIT can guide lung protective ventilator settings: In this scenario, the use of EIT parameters along with findings provided by other medical technologies allows selection of ventilator parameters which provide adequate gas exchange while maintaining optimal lung protection. Since the measures are specific to a particular patient, and reflect their regional distribution of lung recruitability, the selected ventilator settings can help avoid lung damage and inflammation, thus reducing VILI.

- EIT can set lung protective ventilator settings faster: In this scenario, EIT parameters help choose appropriate ventilator settings more quickly. For example, it is common to test the results of a change in PEEP for 15-30 minutes to allow lung tissue and gas exchange to stabilize at a new lung inflation level. EIT could potentially determine much more rapidly when the lungs have stabilized and if the PEEP change was favourable. Such faster settings would make it more feasible to take the time on a busy ward to find appropriate lung protective settings for a patient's ventilation, and to limit the use of chest X-rays and arterial blood gas analysis.

- EIT gives early alarms for dangerous and sub-optimal conditions: In this scenario, EIT images are automatically analyzed to generate alarms in the case of significant deviations of the lung's condition from a previous optimum or of dangerous conditions such as one-sided intubation, pneumothorax, progressively increasing lung collapse, large levels of tidal recruitment, or overinflation.

- EIT images elucidate lung physiology and draw attention of clinical staff: In our experience, EIT images help clarify aspects of lung behaviour which are difficult to understand. In this respect, EIT could serve as a teaching tool. By making such aspects visually clear and intuitive, clinical staff will become more aware of them, and more likely to take them into account when setting patient ventilation. This benefit is likely to be more important in cases where the clinical staff is less experienced with patients suffering from severe lung disease, in smaller regional centres, for example.

- Enable improved weaning (via automated protocols): Weaning of patients from ventilatory support is characterized by a slow decrease of support while avoiding weaning failure caused by too rapid withdrawal. EIT may be able to predict worsening lung function, based on evidence that EIT image parameters may change before a decrease in physiological shunt (Wolf et al 2010). EIT may thus function as early warning indicator.

- Enable therapies that would otherwise not be done: While there is considerable debate as to what levels of PEEP are beneficial or harmful, there is some reluctance 
use larger levels of PEEP in patients who may not clearly benefit from it, because of the risks of overdistension and pneumothorax. EIT monitoring could provide a level of assurance that adverse events could be detected and prevented, allowing the use of such therapies in patients who would not otherwise receive them. (To illustrate how a monitoring technology can enable changes in behaviour, consider the use of a vehicle reverse alarms, which alert the driver as an obstacle is approached. Such an alarm does not enable previously impossible tasks; however, drivers, especially novice ones, become much more ready to park in spaces they would otherwise avoid.)

\section{What do we need to get there?}

In the previous sections, we have argued that EIT is ready to move into clinical applications, and that many possible clinically relevant uses of EIT based parameters have been demonstrated in the literature. There is currently a growing enthusiasm for EIT in these clinical applications. However, much work needs to be done. In this section, we outline a vision for clinical and experimental research and technology development, in order to help bring EIT to clinical use.

\subsection{Clinical and experimental research program}

Research must be focused on relevant outcome variables. First, it is necessary to find adequate interim surrogate outcomes that use EIT. For example, the focus can be on outcomes like: a) shorter time to achieve clinical treatment goals, such as improved oxygenation index; b) less adverse events, such as pneumothorax (Costa et al 2008, Miedema et al 2011); c) less VILI, resulting in reduced markers of inflammation. Many possible EIT measures have been proposed, such as EIT measures of spatial homogeneity of ventilation distribution using: centre of ventilation, (Karsten et al 2011, Frerichs et al 1998), ventilation profiles (Frerichs et al 2006), regional opening and closing pressures (Kunst et al 2000, Pulletz et al 2011), lung filling dynamics (Hahn et al 1996, Kunst et al 2000, Riedel et al 2009, Hinz et al 2007, Miedema et al 2011, Wrigge et al 2008, Frerichs et al 2001, Pham et al 2011) respiratory system compliance (Costa et al 2009, Dargaville et al 2010) and intratidal regional gas distribution (Lowhagen et al 2010). At the present time, we cannot yet investigate mortality and morbidity variables, since these need carefully structured multi-centre trials, and we don't know how to best use EIT in the clinical setting. However, it is essential that EIT be measured against its ability to improve mortality and morbidity rates in order for EIT to become part of routine clinical practice.

We are thus arguing that clinical research studies should focus on whether EIT can be used to measure variables leading to relevant diagnoses (e.g. hyperinflation). These diagnoses would be used to guide patient therapy. Since such EIT-guided therapy is new and unproven, there will be, reasonably, an initial reluctance to give research ethics 
permission. This argues for a need for animal experiments in which EIT-guided therapy is used to treat experimental models of lung injury.

To clarify the clinical research, we give a few examples of research projects which explore interesting, achievable and relevant questions.

- EIT-guided recruitment (for treatment of atelectasis). Hypothesis: EIT-guided recruitment manoeuvres followed by EIT-guided determination of optimal PEEP results in better gas exchange and reduced inflammation. In this case recruitment and PEEP would be selected to achieve the best reduction in EIT measured fractional reversible atelectasis without a large increase in overdistension.

- Fast feedback (for guiding care). Hypothesis: EIT can give feedback in seconds on changes in regional lung function, and this rapid feedback can make faster, safer, and better optimized control of ventilation. For example, studies could investigate whether the selected PEEP is different in patients managed with and without EIT.

- Warnings (quality and safety). Hypothesis: EIT can provide early warnings about sub-optimal ventilation or dangerous conditions. In this case, studies could investigate: 1) During changes in treatment, is the time course of physiological variables different with or without EIT monitoring? 2) With or without an EIT system to warn for pneumothoraces, is the number of events and pattern of care different? 3) Can EIT reliably detect pneumothorax in patients (and validated against X-ray).

- Clinically relevant diagnostic EIT measures (for guiding ventilator settings) Hypothesis: EIT can identify relevant deleterious and favourable phenomena (like cyclic opening and closing of lung units and overdistension on one hand and alveolar recruitment on the other). Studies could compare different EIT indices against each other, for measures of both overdistension and cyclic opening and closing. This would allow determination if patients who require a special manoeuvre (for example a slow inflation) yield comparable measures to those available during ongoing therapeutic ventilation. Also, it should be determined if they can be used in both volume- and pressure-controlled mechanical ventilation.

Much of this work could be facilitated by the creation of an online database of clinical EIT data, which would enhance collaboration and further research, especially by helping EIT groups without access to such data (to develop, for example, more accurate and robust algorithms). Data that has been made available through eidors.org has already gone a long way to facilitating this collaboration.

\subsection{Technology development program}

In this section, we focus on achievable, practical engineering improvements that relate to the current generation of EIT hardware and algorithms. These recommendations are 
meant to be for both the academic engineering researchers and for companies developing EIT products.

The most pressing EIT hardware need is for equipment to be available in sufficient quantities at a reasonable cost. The practical problems associated with electrodes are the most important requirement for image quality. We need to understand what electrode types, shapes, supports, and contact fluid or gel work best with which patients (with also a consideration to placement on preterm infants). Next, there is a requirement for improved patient interfaces, which allow EIT electrodes to be placed quickly, reliably and easily. The electrode support structures/belts recently introduced help address this problem, although they need to be placed with a fairly large tension to achieve adequate stability and electrode contact, which may reduce chest wall compliance.

EIT systems can be optimized in several ways. Most lung EIT systems use stimulation patterns via adjacent or nearby electrodes, which are suboptimal (Adler et al 2011); modifications of these patterns should yield improved signal robustness. Multifrequency EIT promises useful clinical information on tissue types which could make EIT measures more robust. For example, it may be possible to identify oedematous lung tissue, or to distinguish between collapsed (non-ventilated) lung and other tissues. Finally, current configurations place electrodes in a single plane which cannot adequately image 3D distributions of lung ventilation. It is, of course, possible to create 3D images with multiple electrode belts, but the benefit has not been clarified: i.e. what specific imaging advantages are available from two or three electrode planes (Bikker et al 2011, Frerichs et al 1999, Reifferscheid et al 2011), and is this information worth the inconvenience and cost of placing extra belts?

There is now general consensus on the requirements of linear reconstruction algorithms for lung EIT (Adler et al 2009). In addition to these requirements, it is important that the shape of the model domain be roughly right (not simply a circle) and that the very different conductivity of the lungs (vs. most other tissues) be accounted for (Grychtol et al 2011). However, given the consensus on the linear algorithms, there are several other aspects of algorithm behaviour which will need to be validated and tested against models, phantoms or experiments. An understanding of reliable ways to automatically and reproducibly select regions of interest (ROIs) in lung images (Pulletz et al 2006) will need to be developed. As approaches to analyze regional information from EIT images are developed, it will be important to understand and compensate for the partial volume effects (blurring between regions) caused by the limited resolution of the reconstruction algorithm. Similarly, the practical extent to which out-of-electrodeplane conductivity changes affect EIT images is not yet clear. While absolute EIT is not currently sufficiently robust, there is a strong case for using the estimated absolute properties to improve the lung volume measurements. It is common to use frequency domain filtering to select or remove ventilation and cardiac frequencies (Carlisle et al 2010, Dunlop et al 2006, Fagerberg et al 2009, Frerichs et al 2009), and filtering may 
be enhanced using linear transforms (Diebele et al 2008) or a second level of parametric models (Solà et al 2011). Since such filtering loses information, and physiological frequencies (especially cardiac) are not constant, it is important to develop guidance to determine when a filter can lose valuable impedance change information.

Physiological parameters calculated from EIT have largely been based on the change in impedance between end-expiration and end-inspiration. This parameter correlates closely to regional volume changes, and can thus be used as a measure of compliance, provided the driving pressure is known. There is rich information available in the dynamics of the EIT signals, and we encourage work to develop parameters to exploit this information, which should yield: opening/closing pressures; time constants; and measures of overdistension, collapse, and tidal recruitment. Finally, to interface with other medical imaging research and hospital data systems, it must be possible to write EIT images to a standard format. This implies a need to define a DICOM storage class for EIT images.

Clinical EIT systems require usable software to interact with. The user interface must be designed with such clinical interactions and use in mind. Displayed parameters must be easy to interpret and preferably be in physiological units. It is also essential that EIT systems control the quality of data and help the users to correctly interface to patients. Specifically, any errors in electrode contact or incorrect placement should be detected and, if possible, automatically corrected, to avoid the resulting serious image artefacts. The importance of automatic quality control and decision support is underlined by a recent study, showing that the ability of clinicians to detect patientventilator asynchronies is low (Colombo et al 2011).

EIT images and data need to be represented consistently in a clinically useful way. The choice of colours for representing images needs to be consistent. For example, if a set offset to represent FRC is added to the images, it could be misleading unless it were clear that it were just for illustrative purposes. As a sample proposal, a colourmap used by Dräger Medical has been made available (on eidors.org). As more EIT information is simultaneously represented (eg. opening and closing pressures, overdistension and collapse) the consistency of image colour choices will become more important. Another aspect of standardization is the requirement to choose a reference data set for time difference imaging. In some cases the average signal is chosen, while in others, endexpiratory events are identified and used as reference. The requirement for a reference data set can be confusing to EIT users, and it would be useful to have a consistent way to indicate how it is done.

\section{Discussion}

We have presented an assessment of EIT as a tool to help guide lung protective ventilation, synthesizing the presentations of the authors at the "special lung session" of the annual biomedical EIT conferences. We consider lung EIT to be at a time of 
transition. We have the evidence that it is reliable and reproducible. The next question is whether it is relevant and rewarding, ultimately in the sense of whether EIT can help improve patient outcomes. In order to address this question, we recommend to the community (including ourselves) a program of clear, well focused clinical research and of engineering development focused on relevant, applied problems.

At the risk of sounding alarmist, we claim that EIT is at a critical time. There is now a large and growing clinical interest in the technology and commercial devices have been recently introduced to the market. The risk is that the enthusiasm dissipates, as new clinical researchers are unable to reliably use EIT, perhaps by being unable to usefully interpret the images generated, or by having images ruined by electrode errors or interference with other medical devices (Frerichs et al 2011). EIT risks being seen as "yet another technology too complicated for the clinic". Therefore, in this paper, we make recommendations to increase the likelihood of achieving clinical relevance and move EIT closer to positive results. We offer the suggestions: 1) think about the physiology; for example, an EIT measure that "my patient's lungs are 30\% collapsed" may provide deep insights which lead to therapeutic interventions; and 2) analyze EIT images in creative ways; exploit the parameter "time" and many of sophisticated signal processing algorithms to generate new parameters.

To solve these problems, we must work in interdisciplinary teams incorporating clinical, engineering and mathematical experts. EIT data and images should be shared, in standard formats, which we must define. To encourage such interdisciplinary work, we invite the reader looking for collaborators to contact us, and we commit to helping to build such teams. This way we can solve the remaining challenges in bedside lung EIT monitoring, and ultimately improve patient outcomes.

\section{References}

A Adler, PO Gaggero, Y Maimaitijiang. Adjacent Stimulation and Measurement Patterns Considered Harmful. Physiol Meas 32:731-744, 2011.

A Adler, JH Arnold, R Bayford, A Borsic, B Brown, P Dixon, TJC Faes, I Frerichs, H Gagnon, Y Gärber, B Grychtol, G Hahn, WRB Lionheart, A Malik, RP Patterson, J Stocks, A Tizzard, N Weiler, GK Wolf. GREIT: a unified approach to 2D linear EIT reconstruction of lung images. Physiol Meas, 30:S35-S55, 2009.

LA Allaud, MH Martin. Schlumberger, the history of a technique. John Wiley and Sons, New York. 1977.

K Barret, H Brooks, S Boitano, S Barman. Ganong's Review of Medical Physiology. (McGraw-Hill) 23rd Ed, 2009.

IG Bikker, C Preis, M Egal, J Bakker, D Gommers. Electrical impedance tomography measured at two thoracic levels can visualize the ventilation distribution changes at the bedside during a decremental positive end-expiratory lung pressure trial. Crit Care. 15:R193, 2011.

JB Borges, F Suarez-Sipmann, SH Böhm, G Tusman, A Melo, E Maripuu, M Sandström, M Park, EL Costa, G Hedenstierna, M Amato, Regional Lung Perfusion estimated by Electrical Impedance Tomography in a piglet model of lung collapse. In press: J Appl Physiol 2011.

M Bodenstein, M David, K Markstaller. Principles of electrical impedance tomography and its clinical 
application. Crit Care Med 37:713-724, 2009.

A Borsic, A Adler. A Primal Dual-Interior Point Framework for EIT Reconstruction and Regularization with 1-Norm and 2-Norm. EIT Conf 2009, Manchester, UK, 16-19 June, 2009.

BH Brown, DC Barber, AD Leathard, L Lu, W Wang, RH Smallwood, AJ Wilson. High frequency EIT data collection and parameteric imaging. Innov Technol Biol Med 15:1-8, 1994.

BH Brown, AD Seagar. The Sheffield data collection system. Clin Phys Physiol Meas 8(suppl A):91-97, 1987.

HR Carlisle, RK Armstrong, PG Davis, A Schibler, I Frerichs, DG Tingay. Regional distribution of blood volume within the preterm infant thorax during synchronised mechanical ventilation. Intensive Care Med 36:2101-2108, 2010.

D Colombo, G Cammarota, M Alemani, L Carenzo, FL Barra, R Vaschetto, AS Slutsky, F Della Corte, P Navalesi. Efficacy of ventilator waveforms observation in detecting patient-ventilator asynchrony. Crit Care Med 39:2452-2457, 2011.

ELV Costa, CN Chaves, S Gomes, MA Beraldo, MS Volpe, MR Tucci, IAL Schettino, SH Böhm, CRR Carvalho, HE Tanaka, RG Lima, MBP Amato. Real-time detection of pneumothorax using electrical impedance tomography. Crit Care Med, 36:1230-1238, 2008.

ELV Costa, JB Borges, A Melo, F Suarez-Sipmann, C Toufen, SH Böhm, MBP Amato. Bedside estimation of recruitable alveolar collapse and hyperdistension by electrical impedance tomography. Intensive Care Med, 35:1132-1137, 2009.

EL Costa, RG Lima, MB Amato. Electrical impedance tomography. Curr Opin Crit Care 15:18-24, 2009.

PA Dargaville, PC Rimensberger, I Frerichs. Regional tidal ventilation and compliance during a stepwise vital capacity manoeuvre. Int Care Med 36:1953-1961, 2010.

JM Deibele, H Luepschen, S Leonhardt. Dynamic separation of pulmonary and cardiac changes in electrical impedance tomography. Physiol Meas 29:S1-14, 2008.

S Dunlop, J Hough, T Riedel, DF Fraser, K Dunster, A Schibler. Electrical impedance tomography in extremely prematurely born infants and during high frequency oscillatory ventilation analyzed in the frequency domain. Physiol Meas 27:1151-1165, 2006.

A Fagerberg, O Stenqvist, A Aneman. Monitoring pulmonary perfusion by electrical impedance tomography: an evaluation in a pig model. Acta Anaesthesiol Scand 53:152-158, 2009.

I Frerichs, S Pulletz, G Elke, B Gawelczyk, A Frerichs, N Weiler. Patient examinations using electrical impedance tomography-sources of interference in the intensive care unit. Physiol Meas 32:L1-L10, 2011.

I Frerichs, S Pulletz, G Elke, F Reifferscheid, D Schädler, J Scholz, N Weiler. Assessment of Changes in Distribution of Lung Perfusion by Electrical Impedance Tomography. Respiration 77:282-291, 2009.

I Frerichs, PA Dargaville, H van Genderingen, DR Morel, PC Rimensberger. Lung Volume Recruitment after Surfactant Administration Modifies Spatial Distribution of Ventilation. Am J Respir Crit Care Med 174:772-779, 2006.

I Frerichs, T Dudykevych, J Hinz, M Bodenstein, G Hahn, G Hellige Gravity effects on regional lung ventilation determined by functional EIT during parabolic flights. J Appl Physiol 91:39-50, 2001.

I Frerichs, G Hahn, G Hellige. Thoracic electrical impedance tomographic measurements during volume controlled ventilation-effects of tidal volume and positive end-expiratory pressure. IEEE T Med Imaging 18:764-773, 1999.

I Frerichs, G Hahn, W Golisch, M Kurpitz, H Burchardi, G Hellige. Monitoring perioperative changes in distribution of pulmonary ventilation by functional electrical impedance tomography. Acta Anaesth Scand, 42:721-726, 1998.

G Hahn, I Frerichs, M Kleyer, G Hellige. Local mechanics of the lung tissue determined by functional EIT. Physiol Meas 17:A159-A166, 2006.

HR van Genderingen, AJ van Vught, JRC Jansen. Estimation of regional lung volume changes by electrical impedance pressures tomography during a pressure-volume maneuver. Int Care Med 29:233- 
$240,2003$.

B Grychtol, WRB Lionheart, GK Wolf, M Bodenstein, A Adler. The importance of shape: thorax models for GREIT. Conf EIT 2011, Bath, UK, 4-6 May 2011.

JE Hall. Guyton and Hall Textbook of Medical Physiology. (Saunders) 12th Ed, 2011

RP Henderson, JG Webster. An Impedance Camera for Spatially Specific Measurements of the Thorax. IEEE T Biomed Eng 25:250-254, 1978.

J Hinz, A Gehoff, O Moerer, I Frerichs, G Hahn, G Hellige, M Quintel. Regional filling characteristics of the lungs in mechanically ventilated patients with acute lung injury. Eur $J$ Anaesthesiol 24:414-424, 2007.

J Karsten, H Luepschen, M Grossherr, HP Bruch, S Leonhardt, H Gehring, T Meier. Effect of PEEP on regional ventilation during laparoscopic surgery monitored by electrical impedance tomography. Acta Anaesthesiol Scand 55:878-86, 2011.

PWA Kunst, SH Böhm, G Vazquez de Anda, TJC Faes, MBP Amato, B Lachmann, PE Postmus, PMJM de Vries. Regional pressure volume curves by electrical impedance tomography in a model of acute lung injury. Crit Care Med 28:178-183, 2000.

PWA Kunst, G Vazquez de Anda, SH Böhm, TJC Faes, B Lachmann, PE Postmus. PMJM de Vries. Monitoring of recruitment and derecruitment by electrical impedance tomography in a model of acute lung injury. Crit Care Med 28:3891-3895, 2000.

K Lowhagen, S Lundin, O Stenqvist. Regional intratidal gas distribution in acute lung injury and acute respiratory distress syndrome - assessed by electric impedance tomography. Minerva Anestesiol $76: 1024-1035,2010$.

K Lowhagen, K Lindgren, H Odenstedt, O Stenqvist, S Lundin. A new non-radiological method to assess potential lung recruitability: a pilot study in ALI patients. Acta Anaesthesiol Scand 55:165$174,2011$.

S Maisch, SH Böhm, J Solà, MS Goepfert, S Matthias, JC Kubitz, HP Richter, J Ridder, AE Goetz, DA Reuter. Heart-lung interactions measured by electrical impedance tomography. In press: Crit Care Med, 2011.

P Metherall, DC Barber, RH Smallwood, BH Brown. Three Dimensional Electrical Impedance Tomography. Nature, 380:509-512, 1996.

M Miedema, I Frerichs, FH de Jongh, MB van Veenendaal, AH van Kaam. Pneumothorax in a preterm infant monitored by electrical impedance tomography: a case report. Neonatology 99:10-13, 2011.

M Miedema, FH de Jongh, I Frerichs, MB van Veenendaal, AH van Kaam, Changes in Lung Volume and Ventilation During Surfactant Treatment in Ventilated Preterm Infants. Am J Respir Crit Care Med, 184:100-105, 2011.

S Nebuya, M Noshiro, A Yonemoto, S Tateno, BH Brown, RH Smallwood, P Milnes. Study of the optimum level of electrode placement for the evaluation of absolute lung resistivity with the Mk3.5 EIT system. Physiol Meas 27:S129-S137, 2006.

T Riedel, M Kyburz, P Latzin, C Thamrin, U Frey. Regional and overall ventilation inhomogeneities in preterm and term-born infants. Intensive Care Med 35:144-151, 2009.

TMT Pham, M Yuill, C Dakin, A Schibler. Regional ventilation distribution in the first 6 months of life. Eur Respir J 37:919-924, 2011.

S Pulletz, A Adler, M Kott, G Elke, B Gawelczyk, D Schädler, G Zick, N Weiler, I Frerichs. Regional lung opening and closing pressures in patients with acute lung injury. In press: J Critical Care, 2011.

S Pulletz, M Kott, G Elke, D Schaedler, G Zick, J Scholz, N Weiler, I Frerichs. Optimization of artificial ventilation by regional respiratory time constants in patients with acute lung injury. Am J Respir Crit Care Med 179:A3844, 2009.

S Pulletz, HR van Genderingen, G Schmitz, G Zick, D Schädler, J Scholz, N Weiler, I Frerichs. Comparison of different methods to define regions of interest for evaluation of regional lung ventilation by EIT. Physiol Meas 27:S115-S127, 2006.

P Rahmati, M Soleimani, A Adler. Level set based reconstruction algorithm for EIT lung images. Conf 
EIT 2011, Bath, UK, 4-6 May 2011.

F Reifferscheid, G Elke, S Pulletz, B Gawelczyk, I Lautenschläger, M Steinfath, N Weiler, I Frerichs. Regional ventilation distribution determined by electrical impedance tomography: reproducibility and effects of posture and chest plane. Respirology 16:523-531, 2011.

RF Schmidt, F Lang, M Heckmann. Physiologie des Menschen (Springer) 31st Ed, 2011.

HJ Smit, ML Handoko, A Vonk Noordegraaf, TJ Faes, PE Postmus, PM de Vries, A Boonstra. Electrical impedance tomography to measure pulmonary perfusion: is the reproducibility high enough for clinical practice? Physiol Meas 24:491-499, 2003.

J Solà, A Adler, Aldo Santos, G Tusman, F Suárez Sipmann, SH Böhm. Non-invasive monitoring of central blood pressure by Electrical Impedance Tomography (EIT): first experimental evidence. Med Biol Eng Comput, 49:409-415, 2011.

JA Victorino, JB Borges, VN Okamoto, GFJ Matos, MR Tucci, MPR Caramez, H Tanaka, F SuarezSipmann, DCB Santos, CSV Barbas, CRR Carvalho, MBP Amato. Imbalances in Regional Lung Ventilation: A Validation Study on Electrical Impedance Tomography. Am J Respir Crit Care Med, 169:791-800, 2004.

A Vonk-Noordegraaf, A Janse, JT Marcus, JGF Bronzwaer PE Postmus, TJC Faes, PMJM de Vries. Determination of stroke volume by means of electrical impedance tomography Physiol Meas 21:285293, 2000.

GK Wolf, B Grychtol, I Frerichs, D Zurakowski, JH Arnold. Regional lung volume changes during high-frequency oscillatory ventilation. Ped Crit Care Med, 11:610-615, 2010.

H Wrigge, J Zinserling, T Muders, D Varelmann, U Günther, C von der Groeben, A Magnusson, G Hedenstierna, C Putensen. Electrical impedance tomography compared with thoracic computed tomography during a slow inflation maneuver in experimental models of lung injury. Crit Care Med 36:903-909, 2008.

Z Zhao, K Möller, D Steinmann, I Frerichs, J Guttmann. Evaluation of an electrical impedance tomography-based global inhomogeneity index for pulmonary ventilation distribution. Int Care Med 35:1900-1906, 2009. 